\title{
Separation and Simultaneous Quantitation of Montelukast Sodium and Ebastine in Tablets by using Stability-Indicating Liquid Chromatographic Method
}

\author{
Shailesh Koradia ${ }^{1, *}$, Priyal Patel', Ashok Mahajan', Falgun Mehta', Vishwa Chauhan² \\ 'Babaria Institute of Pharmacy, BITS Edu Campus, Vadodara, Gujarat, INDIA. \\ 2Department of Pharmaceutical Chemistry and Quality Assurance, Shree Dhanvantary Pharmacy College, Kim, Surat, Gujarat, INDIA.
}

\begin{abstract}
Objectives: A precise, accurate and selective stability-indicating reverse phase high performance liquid chromatographic assay method has been developed for the simultaneous quantitative determination of Montelukast sodium and Ebastine in tablets. Methods: The chromatographic separation of drugs was attained by using Hypersil octadecyl silane $C_{18}(250 \times 4.6$ $\mathrm{mm}, 5 \mu \mathrm{m}$ ) column at room temperature. The composition of mobile phase was methanol, acetonitrile and $0.02 \mathrm{M}$ ammonium acetate buffer $(\mathrm{pH} 5.5$ adjusted with dilute acetic acid) in the ratio of $80: 15: 05 \mathrm{v} / \mathrm{v} / \mathrm{v}$ and flow rate of mobile phase $1.0 \mathrm{ml} / \mathrm{min}$ with isocratic elution. The signal of eluents was observed at $244 \mathrm{~nm}$ by using diode array detector. Results: The retention time of Montelukast sodium and Ebastine were found to be $4.28 \mathrm{~min}$ and $6.63 \mathrm{~min}$, respectively. The linearity ranges for both drugs were found to be $10-50 \mu \mathrm{g} / \mathrm{ml}$ and the percent recoveries were found to be $99.16 \%$ and $100.12 \%$ for Montelukast sodium and Ebastine respectively. The drug substances and drug products were treated with various forced degradation conditions like acid hydrolysis, alkali hydrolysis, oxidative degradation, thermal degradation and photolytic degradation. The degradants were efficiently separated from the drugs by using optimized chromatographic con-
\end{abstract}

ditions. The developed method was validated as per recommendation parameters of International conference on harmonization guidelines Q2(R1). Conclusion: The validation parameters indicate that the drug substances were efficiently separated from its degradants and developed method can be routinely applied for the simultaneous quantitative determination of Montelukast sodium and Ebastine in combined tablet formulation in the quality control laboratory.

Key words: Quality control laboratory, Montelukast sodium, Ebastine, RPHPLC-DAD method, Validation, ICH guidelines.

\section{Correspondence}

Dr. Shailesh Koradia, M. Pharm., Ph.D.

Professor, Department of Pharmaceutical Chemistry and Quality Assurance, Babaria Institute of Pharmacy, BITS Edu Campus, Vadodara-Mumbai National Highway 8, Vadodara, Gujarat, INDIA.

Phone no: +91-9998931424

Email: shaileshkoradia.bip@bitseducampus.ac.in

DOI: 10.5530/ijpi.2020.1.14

\section{INTRODUCTION}

Montelukast sodium (MNK) is a specific cysteinyl leukotriene receptor antagonist and chemically, 2-[1-[1(R)-[3-[2(E)-(7-chloroquinolin-2-yl) vinyl] phenyl] -3[2-(1-hydroxy-1- methylethyl) phenyl] propylsulfanylmethyl] cyclo-propyl] acetic acid sodium salt. ${ }^{1}$ It is recommended for the treatment of bronchial asthma and to relieve symptoms of allergies. ${ }^{2}$ Ebastine (EBA) is a specific histaminic $\mathrm{H}_{1}$ receptor antagonist and chemically, 4-(4-benzhydryloxy-1-piperidyl)-1- (4-tert-butylphenyl) butan-1-one. It is used for the treatment of allergic rhinitis and chronic idiopathic urticaria. ${ }^{3}$ Montelukast sodium is official in Indian Pharmacopoeia ${ }^{4}$ and Ebastine in bulk drug is official in British Pharmacopoeia. ${ }^{5}$ Literature survey reveals that analytical methods reported for the determination of $\mathrm{MNK}$ and EBA as a single and combination with EBA were UV spectrophotometry, ${ }^{6}$ simultaneous equation spectrophotometric method, ${ }^{7}$ derivative spectrophotometry, ${ }^{8} \mathrm{Q}$-absorbance ratio spectrophotometric method, ${ }^{9}$ HPLC, ${ }^{10}$ RP-HPLC, ${ }^{11}$ LC-MS ${ }^{12}$ and HPTLC $^{13}$ methods. The objective of proposed work is to develop stability indicating RP-HPLC method for the simultaneous estimation of MNK and EBA, in combined tablet dosage dorm. The proposed method was applied for the simultaneous estimation of MNK and EBA in the bulk and marketed formulations. The developed method was validated as per ICH Q2 (R1) guidelines. ${ }^{14}$ The chemical structure of MNK and EBA were shown in Figure 1.

\section{MATERIALS AND METHODS}

\section{Chemicals and Regents}

MNK and EBA drugs as reference standards were procured as gift sample from Morepean Labs Ltd., Himachal Pradesh, India and Kivi Labs Pvt. Ltd., Vadodara, India, respectively. Pharmaceutical dosage form of EBA and MNK (Label claim: $10 \mathrm{mg}$ each) was procured from local drug store. HPLC grade Methanol, acetonitrile and water were purchased from SD Fine-Chem Ltd., Mumbai. Glacial acetic acid, ammonium acetate, sodium hydroxide, hydrochloric acid and hydrogen peroxide used were of AR grade and procured from SD Fine-Chem Ltd., Mumbai. The calibrated glassware was used in this study.

\section{Instrumentation}

The HPLC chromatograph (1220 Infinity, Agilent Technologies Ltd., LCLab, Japan) consisting a gradient pump, auto sampler, diode array detector, thermostatic control column oven. The drugs were separated on a Hypersil octadecyl silane $C_{18}(250 \times 4.6 \mathrm{~mm}, 5 \mu)$ column and measured using Chem Station software. An electronic balance (AX200, Shimadzu, Ltd., Japan), an ultrasonic cleaner (EIE 808, EIE Instruments Pvt. Ltd., India), a digital $\mathrm{pH}$ meter (Toshcon Industries Pvt. Ltd., India) were used in the study. 


\section{Preparation of mobile phase}

Weighed $1.54 \mathrm{~g}$ of ammonium acetate and transferred into $1000 \mathrm{ml}$ glass volumetric flask. The compound was dissolved in water and the $\mathrm{pH} 5.5$ of buffer solution was adjusted with dilute acetic acid. The buffer solution was filtered through $0.45 \mu \mathrm{m}$ nylon filter and degassed before used. The mobile phase comprised of a mixture of methanol, acetonitrile and $0.02 \mathrm{M}$ ammonium acetate ( $\mathrm{pH} 5.5$ adjusted with dilute acetic acid) in the ratio of $80: 15: 05 \mathrm{v} / \mathrm{v} / \mathrm{v}$.

\section{Preparation of stock and standard solutions}

An equivalent amount of $50 \mathrm{mg}$ of MNK and EBA were weighed and transferred to $50 \mathrm{ml}$ volumetric flasks separately. The drugs were dissolved in $20 \mathrm{ml}$ of mobile phase and diluted up to the mark with mobile phase to get $1000 \mu \mathrm{g} / \mathrm{ml}$ concentration of each drug. The solutions were further diluted with mobile phase to obtain the final concentrations of $100 \mu \mathrm{g} / \mathrm{ml}$ of each drug.

\section{Chromatographic conditions}

The RP-HPLC method was carried out with isocratic mode using a mobile phase of methanol: acetonitrile: $0.02 \mathrm{M}$ ammonium acetate, $\mathrm{pH} 5.5$ $(80: 15: 05 \mathrm{v} / \mathrm{v} / \mathrm{v})$ on Hypersil octadecyl silane $\mathrm{C}_{18}(250 \times 4.6 \mathrm{~mm}, 5 \mu \mathrm{m})$ column with $1 \mathrm{ml} / \mathrm{min}$ flow rate and eluents were monitored at $244 \mathrm{~nm}$ by using photodiode array detector. The volume of $20 \mu \mathrm{l}$ sample solution was injected using auto sampler.

\section{Sample preparation of marketed formulation}

The combined tablet marketed formulation (Ebast-M) contained $10 \mathrm{mg}$ of MNK and $10 \mathrm{mg}$ of EBA. Weighed and finely powdered twenty tablets. Weighed accurately a quantity of tablet powder equivalents to about 10 $\mathrm{mg}$ of both the drugs were transferred into $100 \mathrm{ml}$ glass volumetric flask, dissolved the drugs in the minimum amount of solvent and diluted to $100 \mathrm{ml}$ with mobile phase. The solution was filtered through $0.22 \mu$ nylon filter paper and appropriate volume of filtrate was diluted to obtained final concentration of $20 \mu \mathrm{g} / \mathrm{ml}$ of MNK and $20 \mu \mathrm{g} / \mathrm{ml}$ of EBA.

\section{METHODS}

\section{Preparation of calibration curve of Montelukast sodium and Ebastine}

Fixed standard aliquots (1-5 ml) of MNK and EBA were transferred into five different glass volumetric flasks and diluted up to $10 \mathrm{ml}$ with mobile phase to obtained concentrations in the range of $10-50 \mu \mathrm{g} / \mathrm{ml}$ of MNK and EBA. The fixed volume of sample was injected into the chromatograph with the help of auto sampler and chromatograms of each sample were recorded with optimized chromatographic conditions. Calibration curves were prepared by plotting peak areas versus concentrations and regression equations were calculated for MNK and EBA.

\section{Linearity and Range}

The linearity of the method was performed by analyzing five different concentrations $(10-50 \mu \mathrm{g} / \mathrm{ml})$ of the standard drug solutions of MNK and EBA separately. The calibration curve was plotted by using the peak area versus concentration. The correlation co-efficient, slope, intercept and regression line equations were find out from the calibration graph.

\section{Accuracy}

The accuracy parameter was performed by calculating percent recovery of MNK and EBA in the pre-analysed sample. The known amount of pure drugs corresponding to 80,100 and $120 \%$ of labelled value has been added into pre-analysed sample. The $20 \mu \mathrm{l}$ of sample solution was injected in the chromatograph using auto sampler injector.

\section{Precision}

The repeatability of method was performed by analyzing MNK and EBS $(30 \mu \mathrm{g} / \mathrm{ml})$ respectively for six times $(n=6)$ by developed RP-HPLC method and the \% RSD was calculated. Precision of the developed method was performed by intraday and inter day variation studies. Aliquots of three different concentrations $(10 \mu \mathrm{g} / \mathrm{ml}, 20 \mu \mathrm{g} / \mathrm{ml}, 30 \mu \mathrm{g} / \mathrm{ml})$ of MNK and EBA were analysing responses three times on the same day and on three consecutive days for intraday and inter day precision, respectively.

\section{Quantitation limits}

The detection limit (LOD) and quantification limit (LOQ) were calculated as per equation given in the $\mathrm{ICH}$ guidelines: $\mathrm{LOD}=3.3(\mathrm{SD}) / \mathrm{S}$ and $\mathrm{LOQ}=10(\mathrm{SD}) / \mathrm{S}$, where $\mathrm{SD}=$ standard deviation of peak area and $\mathrm{S}=\mathrm{av}$ erage slope of the calibration curve.

\section{Robustness}

Robustness of chromatographic method was checked by making small deliberate changes in some chromatographic conditions-change in flow rate, $\mathrm{pH}$ and composition of mobile phase and results were examined. The samples of both drugs were injected into chromatograph in triplicate and chromatograms were developed using optimized chromatographic conditions.

\section{System suitability parameters}

System suitability tests were performed to verify reproducibility of the chromatographic system. The $20 \mu \mathrm{l}$ sample solutions of both the drugs were repetitively injected into the chromatograph under optimized chromatographic conditions and parameters such as retention time, theoretical plates, capacity factor, resolution and peak asymmetry were studied to evaluate the system suitability of the method.

\section{Forced degradation studies}

The stress degradation studies of bulk drug and tablet formulation were performed under various conditions like, hydrolytic, oxidative, photolytic and thermolytic stress conditions.

\section{Acid degradation}

In acid degradation study, aliquots of $1 \mathrm{ml}$ of stock solution $(1000 \mu \mathrm{g} /$ $\mathrm{ml}$ ) of MNK, EBA and combined drugs were transferred into $10 \mathrm{ml}$ glass volumetric flasks separately followed by addition of $1 \mathrm{ml}$ of $0.1 \mathrm{~N} \mathrm{HCl}$ to each volumetric flask. All these glass volumetric flasks were kept at room temperature for $2 \mathrm{hr}$. The solutions were neutralized with $0.1 \mathrm{~N} \mathrm{NaOH}$ and diluted up to $10 \mathrm{ml}$ with mobile phase to get final concentrations of each volumetric flask of $100 \mu \mathrm{g} / \mathrm{ml}$. The suitable aliquots were taken from the resultant solutions and finally $10 \mu \mathrm{g} / \mathrm{ml}$ of MNK, EBA and combined drug solution was prepared.

\section{Alkali degradation}

In alkali hydrolysis study, aliquots of $1 \mathrm{ml}$ of stock solution $(1000 \mu \mathrm{g} /$ $\mathrm{ml}$ ) of MNK, EBA and combined drugs were transferred into $10 \mathrm{ml}$ glass volumetric flasks separately followed by addition of $1 \mathrm{ml}$ of $1 \mathrm{~N} \mathrm{NaOH}$ to each volumetric flask. All these glass volumetric flasks were kept at $60^{\circ} \mathrm{C}$ for $1 \mathrm{hr}$. The solutions were neutralized with $1 \mathrm{~N} \mathrm{HCl}$ and diluted up to 10 $\mathrm{ml}$ with mobile phase to get final concentrations of each volumetric flask of $100 \mu \mathrm{g} / \mathrm{ml}$. The suitable aliquots were taken from the resultant solutions and finally $10 \mu \mathrm{g} / \mathrm{ml}$ of MNK, EBA and combined drug solution was prepared.

\section{Oxidative degradation}

To performed oxidative degradation, $1 \mathrm{ml}$ of stock solution $(1000 \mu \mathrm{g} /$ $\mathrm{ml}$ ) of MNK, EBA and combined drugs were transferred into $10 \mathrm{ml}$ glass 
volumetric flasks separately followed by addition of $1 \mathrm{ml}$ of $3 \%$ hydrogen peroxide $\left(\mathrm{H}_{2} \mathrm{O}_{2}\right)$ to each volumetric flask. All these glass volumetric flasks were kept at room temperature for $24 \mathrm{hrs}$. All these solutions were warmed to remove excess of hydrogen peroxide and diluted up to $10 \mathrm{ml}$ with mobile phase to get final concentrations of each glass volumetric flask of $100 \mu \mathrm{g} / \mathrm{ml}$. Appropriate aliquots were taken from the above solutions and finally $10 \mu \mathrm{g} / \mathrm{ml}$ of MNK, EBA and combined drug solution was prepared.

\section{Thermal degradation}

For thermal degradation, bulk drugs and tablets powder were exposed in a hot air oven at $60^{\circ} \mathrm{C}$ for $2 \mathrm{hr}$. After $2 \mathrm{hr}$, accurately weighed $10 \mathrm{mg}$ of each drug sample and transferred individually into $10 \mathrm{ml}$ glass volumetric flasks stock solution of $1000 \mu \mathrm{g} / \mathrm{ml}$ prepare with mobile phase. Appropriate aliquots were taken from the resultant solutions and finally prepare the concentration of $10 \mu \mathrm{g} / \mathrm{ml}$ of $\mathrm{MNK}$, EBA and combined drug was prepared.

\section{Photolytic degradation}

In the photolytic degradation bulk drugs and tablets powder were exposed under ultraviolet light at $254 \mathrm{~nm}$ for $24 \mathrm{hrs}$. After $24 \mathrm{hr}$, accurately weighed $10 \mathrm{mg}$ of each drug sample and transferred individually into $10 \mathrm{ml}$ glass volumetric flasks stock solution of $1000 \mu \mathrm{g} / \mathrm{ml}$ prepare with mobile phase. Appropriate aliquots were taken from the resultant solutions and finally prepare the concentration of $10 \mu \mathrm{g} / \mathrm{ml}$ of MNK, EBA and combined drug was prepared.

\section{RESULTS}

\section{Method development and optimization}

The chromatographic separation and quantitation of drugs in presence of its degradants was carried out with isocratic mode on a Hypersil octadecyl silane $\mathrm{C}_{18}(250 \times 4.6 \mathrm{~mm}, 5 \mu \mathrm{m})$ reverse phase column with 1.0 $\mathrm{ml} / \mathrm{min}$ flow rate. The mobile phase having composition of methanol: acetonitrile: $0.02 \mathrm{M}$ ammonium acetate, pH 5.5 (80:15:05 v/v/v) showed efficient resolution of peak in the presence of degradation products and impurities. The volume of $20 \mu \mathrm{l}$ sample solution was injected using auto sampler. The drugs were monitored at $244 \mathrm{~nm}$ by using photodiode array detector. The retention time of MNK and EBA under optimized chromatographic conditions was $4.28 \mathrm{~min}$ and $6.63 \mathrm{~min}$, respectively. The straight baseline was observed in the blank chromatogram of mobile phase and both the drugs were effectively resolved in bulk and formulation (Figure 2). The system suitability of method was checked by evaluating the parameters like, resolution, tailing factor, theoretical plates and reproducibility. The results of system suitability parameters were observed within the specified limits according to ICH guidelines (Table 1).

\section{Validation \\ Linearity and Range}

The linearity of method was checked by analyzing five different concentrations levels of the standard drug solutions of MNK and EBA separately. The linearity for both the drugs was found to be $10^{-}-50 \mu \mathrm{g} / \mathrm{ml}$. The correlation co-efficient and regression equations were calculated from the calibration curve. The selected lower range and upper range of the linearity was $10 \mu \mathrm{g} / \mathrm{ml}$ and $20 \mu \mathrm{g} / \mathrm{ml}$, respectively.

\section{Precision and accuracy}

The low values of $\%$ RSD for of repeatability of method, intraday precision and interday precision for both the drugs divulge that developed method is precise. The recovery experiments were conducted for the determination of accuracy of analytical method; known concentration of standard drug was added into pre-analysed sample at three different levels, 50, 100 and $150 \%$. The percent recovery of drug was calculated from the regression equations (Table 2).

\section{Sensitivity and Specificity}

Limits of detection and quantitation were based on the standard deviation and the slope of the calibration plots. The estimation of limit of detection (LOD) and limit of quantitation (LOQ) considered the acceptable signal-to-noise ratios 3:1 and 10:1, respectively. LOD of MNK and EBA were $0.169 \mu \mathrm{g} / \mathrm{ml}$ and $0.195 \mu \mathrm{g} / \mathrm{ml}$ respectively. LOQ of MNK and EBA were $0.510 \mu \mathrm{g} / \mathrm{ml}$ and $0.593 \mu \mathrm{g} / \mathrm{ml}$ respectively. The chromatograms of degradation studies and assay results of tablets confirmed that there was no interference of drugs with degradants and excipients of formulation. The 3D chromatograms and peak purities of the stressed samples were performed using DAD detector and peak purity data of samples indicate the specificity of analytical method. The robustness parameter of the method was checked by injecting the $100 \%$ sample concentration to small changes in the chromatographic conditions like, flow rate, $\mathrm{pH}$ of mobile phase and mobile phase composition and the $\%$ RSD of each variable was calculated (Table 3 ).

\section{Forced degradation studies}

The stress degradation studies indicate that both the drugs were susceptible to acid, alkali, oxidation, photolytic and thermolytic conditions. The chromatograms of degraded samples of bulk drug and tablet indicate well separation of drugs from degradants (Figure 3). The 3D chromatograms of different stressed conditions of sample indicate that the drug

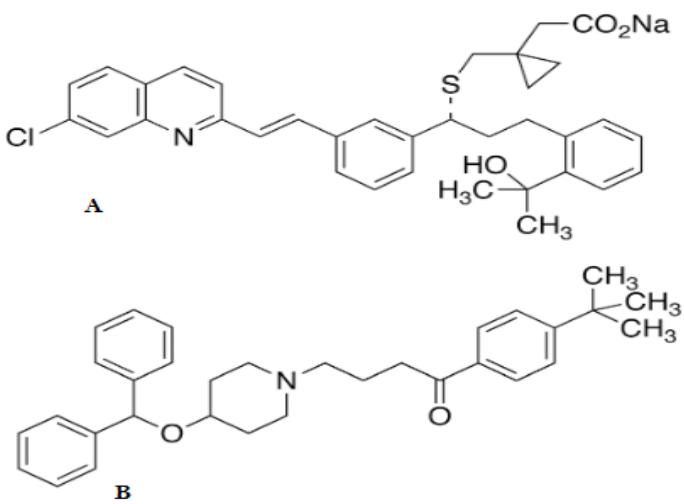

Figure 1: Chemical structure of (A) Montelukast sodium and (B) Ebastine.

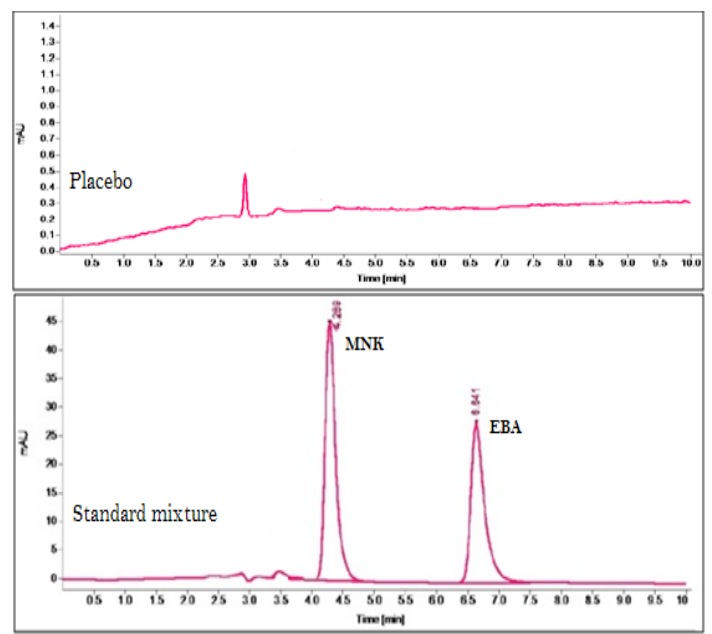

Figure 2: Typical HPLC chromatogram of placebo and standard mixture of drugs (Retention time of Montelukast sodium $=4.28 \mathrm{~min}$. and Ebastine $=$ $6.63 \mathrm{~min})$. 


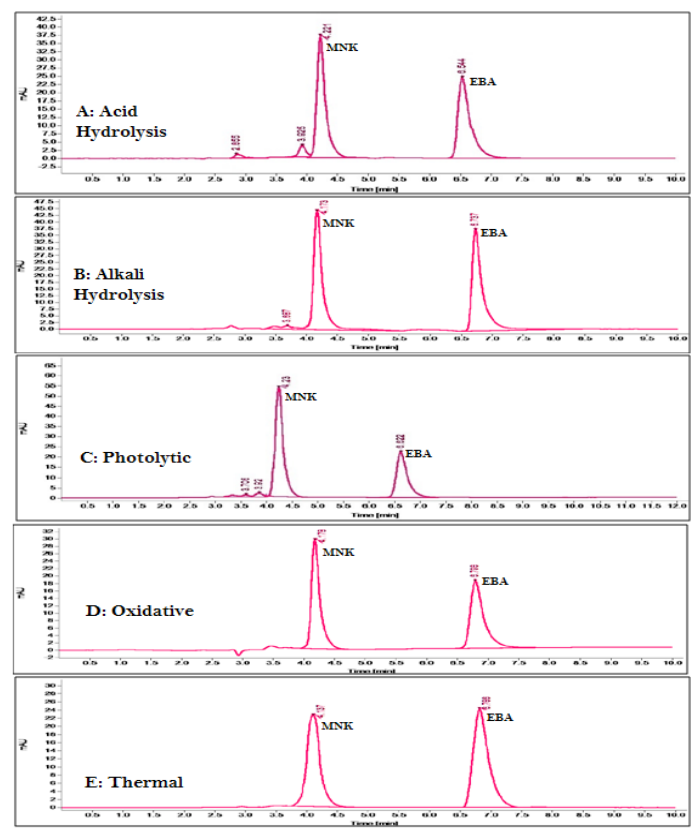

Figure 3: Chromatograms of acid degradation (A); alkali degradation (B); Photolytic degradation $(C)$; oxidative degradation (D) and thermal degradation (E), where retention time of MNK at $4.28 \mathrm{~min}$ and EBA at $6.64 \mathrm{~min}$.

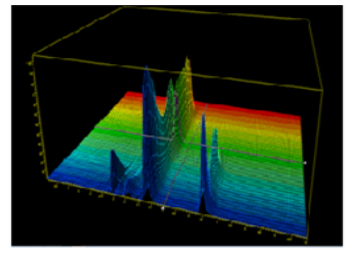

A. Acid Hydrolysis

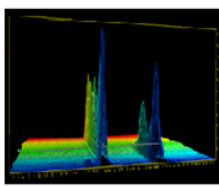

C. Oxidative

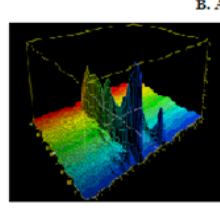

D. Photolytic

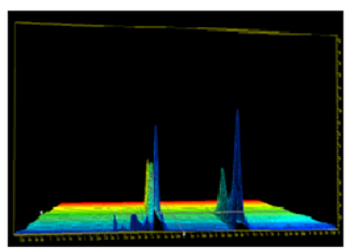

B. Alkali Hydrolysis

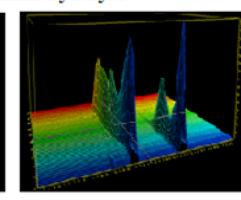

E. Thermolytic
Figure 4: 3D HPLC chromatograms of acid degradation (A); alkali degradation (B); Photolytic degradation (C); oxidative degradation (D) and thermolytic degradation (E).

substances were resolved from impurities as well as degradants (Figure 4). The percent content of drugs after degradation were calculated by comparing the areas of the drugs in each condition with the corresponding peak areas of both the drugs under normal condition (Table 4).

\section{Assay of marketed formulation}

The $20 \mu \mathrm{g} / \mathrm{ml}$ sample solution of MNK and EBA was prepared as per procedure mentioned earlier. Assay of marketed tablets formulation was performed in triplicate under the optimized chromatographic conditions and percent content of drugs was calculated from the regression equations of calibration curves of MNK and EBA respectively. The mean percent content of MNK and EBA from calibration curves were found to be $99.43 \%$ and $101.36 \%$ respectively. None of excipients of tablet formulation interfered with the analyte peaks of drug molecules. The \% RSD for all method parameters was observed within limits, which indicate the validity of method and percent content of drugs obtained by this method are in limits.
Table 1: System suitability parameters of Montelukast sodium and Ebastine.

\begin{tabular}{ccc}
\hline Parameters & Results of MNK & Results of EBA \\
\hline \% RSD of peak area & 0.21 & 0.13 \\
\% RSD of retention time & 0.43 & 0.39 \\
Theoretical plates (N) & 3309 & 5239 \\
Tailing factor (T) & 0.71 & 0.59 \\
Resolution (R) & --- & 7.08 \\
\hline
\end{tabular}

Table 2: Accuracy data of Montelukast sodium and Ebastine.

\begin{tabular}{ccccc}
\hline Parameter & $\begin{array}{c}\text { Amount } \\
\text { added } \\
(\mu \mathrm{g} / \mathrm{ml})\end{array}$ & $\begin{array}{c}\text { Amount } \\
\text { recovered }(\mu \mathrm{g} / \\
\mathrm{ml})\end{array}$ & $\begin{array}{c}\text { \% Recovery } \\
\text { Mean } \pm \text { SD } \\
(\mathrm{n}=3)\end{array}$ & $\begin{array}{c}\text { Mean } \\
\% \\
\text { Recovery }\end{array}$ \\
\hline MNK & & & & \\
$50 \%$ level & 10 & 9.90 & $99.00 \pm 0.75$ & \\
$100 \%$ level & 20 & 19.86 & $99.32 \pm 0.83$ & 99.16 \\
$150 \%$ level & 30 & 29.75 & $99.17 \pm 0.65$ & \\
EBA & & & & \\
$50 \%$ level & 10 & 10.03 & $100.01 \pm$ & \\
& & & 0.92 & \\
$100 \%$ level & 20 & 20.07 & $100.36 \pm$ & 100.12 \\
$150 \%$ level & 30 & 30.00 & $100.00 \pm$ & \\
& & & 0.53 & \\
\hline
\end{tabular}

Table 3: Summary of method validation parameters.

\begin{tabular}{ccc}
\hline Parameters & $\begin{array}{c}\text { Montelukast } \\
\text { Sodium }\end{array}$ & Ebastine \\
\hline Linearity $(\mu \mathrm{g} / \mathrm{ml})$ & $10-50$ & $10-50$ \\
Slope $(\mathrm{m})$ & 73.81 & 39.10 \\
Intercept $(\mathrm{c})$ & -59.58 & 12.54 \\
Correlation coefficient $\left(\mathrm{r}^{2}\right)$ & 0.9996 & 0.9992 \\
Regression equation & $\mathrm{y}=73.81 \mathrm{x}-59.58$ & $\mathrm{y}=39.1 \mathrm{x}+12.54$ \\
LOD $(\mu \mathrm{g} / \mathrm{ml})$ & 0.169 & 0.195 \\
LOQ $(\mu \mathrm{g} / \mathrm{ml})$ & 0.510 & 0.593 \\
Repeatability $(\% \mathrm{RSD}$, & 0.81 & 0.49 \\
$n=6)$ & & \\
Precision $(\% \mathrm{RSD})$ & $0.28-0.87$ & $0.67-0.74$ \\
Intraday $(n=3)$ & $0.65-0.97$ & $0.75-1.02$ \\
Interday $(n=3)$ & & $0.31-0.81$ \\
Robustness $(\%$ RSD) & $0.36-0.57$ & $0.23-0.84$ \\
Flow rate change & $0.27-0.63$ & $0.17-0.30$ \\
\hline pH of mobile phase change & $0.11-0.47$ & \\
Mobile phase ratio change & & \\
\hline
\end{tabular}

\section{Stability of solution}

The sample and mobile phase stability studies were checked at intervals of $6 \mathrm{hr}, 12 \mathrm{hr}$ and $24 \mathrm{hr}$ at room temperature. The peak area of sample was measured at particular intervals by using optimized chromatographic conditions. Form the results; it was found that the sample solution and mobile phase was stable for more than $24 \mathrm{hr}$ at room temperature. 
Table 4: Summary of forced degradation studies.

\begin{tabular}{|c|c|c|c|c|}
\hline \multirow{2}{*}{$\begin{array}{l}\text { Description of stress } \\
\text { condition }\end{array}$} & \multicolumn{2}{|c|}{$\begin{array}{l}\text { Content of drug } \\
\text { after degradation } \\
\qquad(n=3)\end{array}$} & \multicolumn{2}{|c|}{ Peak purity index } \\
\hline & MNK & EBA & MNK & EBA \\
\hline $\begin{array}{l}\text { Acidic } / 0.1 \mathrm{~N} \mathrm{HCl} / 2 \mathrm{hrs} / \\
\text { solution }\end{array}$ & 81.98 & 85.05 & 0.99791 & 0.99739 \\
\hline $\begin{array}{l}\text { Alkali } / 1 \mathrm{~N} \mathrm{NaOH} / 60^{\circ} \mathrm{C} / 1 \mathrm{hr} / \\
\text { solution }\end{array}$ & 77.16 & 89.84 & 0.99851 & 0.99769 \\
\hline $\begin{array}{l}\text { Photo/under UV light/24 hrs/ } \\
\text { solid }\end{array}$ & 81.56 & 82.07 & 0.99862 & 0.99901 \\
\hline $\begin{array}{c}\text { Oxidative } / 3 \% \mathrm{H}_{2} \mathrm{O}_{2} / 24 \mathrm{hrs} / \\
\text { solution }\end{array}$ & 79.87 & 81.64 & 0.99918 & 0.99949 \\
\hline Thermal $/ 50^{\circ} \mathrm{C} / 2 \mathrm{hrs} /$ solid & 83.45 & 93.43 & 0.99895 & 0.99997 \\
\hline
\end{tabular}

\section{DISCUSSION}

In the present developed method, the selected drug substances having different physicochemical parameters such as solubility, polarity of drug molecules and dissociation constants. The physiochemical parameters of individual drug molecules were studied and suitable analytical wavelength for the simultaneous quantitative estimation of MNK and EBA was determined by using diode array detector. Based on literature and data of physicochemical parameters, various compositions of mobile phases were tried for effective separation of drugs in the presence of degradants. The effect of chromatographic variables such as detection wavelength, stationary phase, mobile phase compositions, $\mathrm{pH}$ of mobile phase and flow rate were studied to optimized preeminent chromatographic conditions. In this study, firstly various compositions of mobile phase having polar solvents like acetonitrile, methanol and water in different ratios and different $\mathrm{pH}$ were tried for the simultaneous elution of selected drug substances. When mixture of methanol and water was used as mobile phase, then peaks were merged and showed broadening. In mixture of acetonitrile: water peaks showed poor resolution. So, buffer solution was tried to optimized chromatographic conditions. The mobile phase with composition of methanol: acetonitrile: $0.02 \mathrm{M}$ ammonium acetate, $\mathrm{pH} 5.5$ adjusted with acetic acid (80:15:05 v/v/v) showed efficient and fast separation of selected drug substances and their degradants formed during forced degradation study.

The system suitability of method was checked by evaluating the parameters like, capacity factor, resolution, tailing factor, theoretical plates and reproducibility. The present work was carried out on Hypersil octadesyl silane $\mathrm{C}_{18}(250 \times 4.6 \mathrm{~mm}, 5 \mu \mathrm{m})$ column at room temperature which showed better reproducibility and low back pressure. The results of system suitability test parameters were observed within the specified limits as per recommendations of International Conference on Harmonization (ICH) guidelines. The straight baseline was observed in the blank chromatogram of mobile phase and both the drugs were effectively resolved in bulk and formulation.

The estimated limits of detection and limits of quantitation values confirmed that the method is sufficiently sensitive for the detection of drug in the presence of their degradants. Also, percent recoveries of the drugs were found to be within acceptable limits. Specificity of the method was assessed by percent recovery study of both the drugs when analyzed in combination. It was observed that the peaks of each of the drugs were well separated and not interfering with excipients as well as degradants. Thus, it confirmed the method is specific to each of the two drugs in combination. The statistical data obtained during robustness study indicate that the developed method is robust.
In the degradation study, it was observed that both the drugs were susceptible to hydrolysis, oxidation, thermolysis and Photolysis. Montelukast sodium shows two degradants in the acidic condition showing that it is more sensitive acidic conditions ( $0.1 \mathrm{~N}$ hydrochloric acid). Ebastine is less sensitive to alkali condition ( $1 \mathrm{~N}$ sodium hydroxide) compared to Montelukast sodium. Montelukast sodium shows two degradants and Ebastine show one degradants under exposure of the ultraviolet radiation. Montelukast sodium and Ebastine are almost equally susceptible in oxidative stress condition ( $3 \%$ hydrogen peroxide). Under thermal degradation it was observed that Ebastine is less degraded than Montelukast sodium. Form the above discussion it was included that Montelukast sodium is more susceptible to various stress degradation condition compared to Ebastine. The chromatograms of stability study indicate that all degraded products which were produced in the different stress conditions showed efficient resolution from the drug peaks.

\section{CONCLUSION}

A specific, rapid, accurate and precise stability-indicating liquid chromatographic method was developed for the quantitation of Montelukast sodium and EBA in the combined tablets using diode array detector. The ICH recommendations method validation parameters suggested that proposed method successfully separated two drugs with its degradants. The developed stability-indicating RP-HPLC method could be routinely used in the quality control department for the quantitative determination of drugs.

\section{ACKNOWLEDGEMENT}

The authors thank Morepean Labs Ltd., Himachal Pradesh, India and Kivi Labs Pvt. Ltd., Vadodara, India for providing gift sample of Montelukast sodium and Ebastine, respectively.

\section{CONFLICT OF INTEREST}

The authors declare no conflict of interest.

\section{ABBREVIATIONS}

ICH: International Conference on Harmonization; RP-HPLC: Reversed Phase High Performance Liquid Chromatography; DAD: Diode Array Detector; MNK: Montelukast sodium; EBA: Ebastine; LOD: Limit of Detection; LOQ: Limit of Quantitation; SD: Standard Deviation; RSD: Relative Standard Deviation; RS: Reference Standard; HPTLC: High Performance Thin Layer Chromatography; LC-MS: Liquid Chromatography Mass Spectrometry; UV: Ultra Violet; AR: Analytical Reagent; RS: Reference standard.

\section{REFERENCES}

1. The Merck Index. $14^{\text {th }}$ ed. New Jersey: Merck Research Laboratories. 2006;591.

2. Rang HP, Dale MM, Ritter JN, Moore PK. Pharmacology. $6^{\text {th }}$ ed. Edinburgh, New York: Churchill Livingstone. 2008;361-3.

3. Tripathi KD. Essential of Medical Pharmacology. $6^{\text {th }}$ ed. New Delhi: Jaypee Brothers Ltd. 2008;222-3.

4. Indian Pharmacopoeia. Controller of Publication, Govt. of India, Ministry of Health and Family Welfare, New Delhi. 2010;2:1704-6.

5. British Pharmacopoeia. HMSO Publication, London. 2016;1:735.

6. Kamyar P, Zahra MK, Alireza G, Mahmoud RS, Hossein A. Spectrophotometric determination of Cetrizine and Montelukast in prepared formulations. Int J Pharm Sci. 2011;3(2):12830

7. Savsani J, Goti P, Patel P. Development and validation of simultaneous equation method for estimation of Ebastine and Montelukast sodium in combined tablet dosage form. Der Pharmacia Sinica. 2012;3(6):690-8

8. Rana N, Patel N, Limbachiya U, Pasha TY. Derivative Spectrophotometric method for simultaneous estimation of Montelukast sodium and Ebastine in bulk and their combined tablet dosage form. Asian J Res Chem. 2013;6(3):232-5.

9. Savsani J, Goti P, Patel P. "Simultaneous UV spectrophotometric method for estimation of Ebastine and Montelukast sodium in tablet dosage form by Q-ratio 
method". Int J Chem Tech Res. 2013;5(1):47-55.

10. Baokar S, Ranpise N. Analytical method development and validation for simultaneous estimation of Montelukast and Ebastine by HPLC. Res J Pharm Tech. 2015;8(1):1-5.

11. Rana N, Patel N, Limbachiya U, Pasha TY. Development and validation of RPHPLC method for the simultaneous estimation of Montelukast sodium and Ebastine in tablet dosage form. Indian J Pharm Sci. 2013;75(5):599-602.
12. Kang W, Liu KH, Ryu JY, Shin JG. Simultaneous determination of Ebastine and its three metabolites in plasma using liquid chromatographytandem mass spectrometry. J Chromatogr B Analyt Technol Biomed Life Sci. 2004;813(1-2):7580.

13. Rote A, Niphade V. Determination of Montelukast sodium and Levocetirizine dihydrochloride in combined tablet dosage form by HPTLC and firstderivative spectrophotometry. J Liq Chromatogr Relat Technol. 2011;34(3):15567.

14. ICH Q2 (R1). Validation of analytical procedures: Text and Methodology, International Conference on Harmonization, Secretariat, Geneva. 2005.

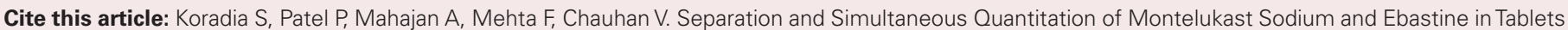
by using Stability-Indicating Liquid Chromatographic Method. Int. J. Pharm. Investigation. 2020;10(1):76-81. 